\title{
Edible film based on candelilla wax to improve the shelf life and quality of avocado
}

\author{
Saul Saucedo-Pompa ${ }^{\mathrm{a}}$, Romeo Rojas-Molina ${ }^{\mathrm{b}}$, Antonio F. Aguilera-Carbó ${ }^{\mathrm{b}}$, Aide Saenz-Galindo ${ }^{\mathrm{a}}$, \\ Heliodoro de La Garza ${ }^{\text {, Diana Jasso-Cantú }}{ }^{\mathrm{b}}$, Cristóbal N. Aguilar ${ }^{\mathrm{a}, *}$ \\ ${ }^{a}$ Department of Food Science and Technology, School of Chemistry, Universidad Autónoma de Coahuila, Blvd. Venustiano Carranza, 25280 Saltillo, Coahuila, Mexico \\ b Universidad Autónoma Agraria “Antonio Narro" Calzada Antonio Narro 1923, Buenavista, Saltillo, Coahuila, Mexico
}

\section{A R T I C L E I N F O}

\section{Article history:}

Received 22 November 2008

Accepted 18 February 2009

Keywords:

Candelilla wax

Colletotrichum gloeosporioides

Avocado

Ellagic acid

\begin{abstract}
A B S T R A C T
In this study the effect of addition of ellagic acid (at three different concentrations) into candelilla wax matrix on shelf life and quality of whole avocados was studied. Control treatments were avocados coated with candelilla wax without ellagic acid and avocados without coating. The fruits were chosen for their maturity, size, free from infection and physical defects. All those samples were inoculated with a concentrated suspension of spores of Colletotrichum gloeosporioides, the main phytopathogenic fungus for avocados. Experiments were carried out completely divided into randomized groups. Changes in appearance, solids content, $\mathrm{pH}, a_{\mathrm{w}}$, lightness ( $L^{*}$ value) and weight loss were monitored during 6 weeks every 8 days. A sensory evaluation of avocados coated with the best edible film was also performed. Edibel films were able to reduce significantly the damage caused by $C$. gloeosporioides, reducing also significantly the change in appearance and weight loss in the fruits. Use of ellagic acid as part of the edible film has an important effect to improve the quality and shelf life of avocado. With this work we found that using this new protection system the negative effects of $C$. gloeosporioides can be successfully reduced.

(c) 2009 Elsevier Ltd. All rights reserved.
\end{abstract}

\section{Introduction}

In recent years, food packaging research has focused more on biodegradable films, including films made from plant sources (Sey$\operatorname{dim}$ \& Sarikus, 2006). Because consumers demand less use of chemicals on minimally processed fruits and vegetables, more attention has been paid to search for naturally occurring substances able to act as alternative antimicrobials and antioxidants. The ability of edible films to retard moisture, oxygen, aromas and solute transport may be improved by including additives such as antioxidants, antimicrobials, colorants, flavors, fortifying nutrients and spices in film formulation (Pranoto, Rakshit, \& Salokhe, 2005). Besides incorporation of antimicrobial agents into packaging materials has also become very popular since oxidation is a major problem affecting the food quality (Mecitoflu-Güçbilmez, Yemenicioflu, \& Arslanoflu, 2007).

Antimicrobial packaging is a form of active packaging that could extend the shelf life of food products while providing microbial safety for consumers (Rooney, 1995). It acts by reducing, inhibiting, or retarding the growth of pathogen microorganisms in packed foods and packaging material (Vermeiren, Devlieghere, van Beest, de Kruiif, \& Debevere, 1999). The coating can serve as a carrier for antimicrobial compounds and/or antioxidants compounds in order to maintain high concentrations of

\footnotetext{
* Corresponding author. Tel.: +52 844416 1238; fax: +52 8444159534 .

E-mail address: cristobal.aguilar@mail.uadec.mx (C.N. Aguilar).
}

preservatives on the food surfaces (Oussallah, Caillet, Salmieri, Saucier, \& Lacroix, 2004). Several compounds have been proposed for antimicrobial activity in food packaging, including organic acids, enzymes such as lysozyme, and fungicides such as benomyl, imazalil and natural antimicrobial compounds such as spices (Tharanathan, 2003a, b).

To develop these films, it is necessary to consider the mechanical, physical and chemical factors involved in the storage of fruits. In addition, these films can confer nutritional and organoleptic properties to the food if added as antioxidants, colorants or artificial flavors (Saucedo-Pompa, Jasso-Cantu, Ventura-Sobrevilla, Sáenz-Galindo, \& Aguilar, 2007).

The use of edible films cannot replace the use of traditional packaging materials, but it is necessary to take into account their functional characteristics and the possible advantages in certain applications (Baldwin, Medlar-Carriedo, \& Baker, 1995). The influence of an additive will depend on their concentration, chemical structure, degree of dispersion in the film and degree of interaction with the polymer (Kester \& Fennema, 1986). If there is an adequate homogenization of the system it is possible to ensure uniformity in the size and distribution of particles dispersed phase, improving the barrier functionality against the mass transfer of the formed film (Bosquez-Molina, 2005).

The candelilla wax is a complex substance of vegetable origin, insoluble in water, but highly soluble in acetone, chloroform, benzene and other organic solvents, is characterized by a high content of hydrocarbons (around 50\%) and a relatively low quantity of vol- 
atile esters and is recognized by the FDA as a substance GRASS for application in the foods industry (Saucedo Pompa, 2007).

Tannins are secondary metabolites present in these plants. Some of the principal components of these substances are the ellagic and gallic acids. Several medicinal and industrial applications have been found for these acids such as antitumoral, antioxidant, antimicrobial, antiviral and antiinflammatory. In addition, some of them may reduce heart disease (Khanbabaee \& Van Ree 2001; Ventura et al., 2008).

The ellagic acid present in grapes, strawberries, blackberries, blueberries, nuts and other foods is a type of phenolic compound that acts as an antioxidant; however, they are not easily available and can vary in effectiveness depending on if they are used in their natural form or purified. Such compounds may also protect against ultraviolet light, attack by insects and microorganisms. In order to be bioavailable, ellargic acid needs to be in a form under which the cell can recognize it and use it. This may be the free chemical form or in a combined form with another biomolecule; in general, ellargic acid combines itself with molecules of sugar (Vasconcellos, 1994).

Mexico is the largest producer of avocados in the world (Saucedo-Pompa, Jasso-Cantu, Rojas-Molina, Sáenz-Galindo, \& Aguilar, 2008), however this country faces several requests for approving the exportation of the avocados to the United States and Europe. In addition, the shelf life of these fruits is very short and their quality is seriously affected by the attack of phytopathogenic fungi, mainly Colletotrichum gloesporioides. For this reason in the last 14 years, growers and packers are developing grove management techniques, packing practices and shipping practices in order to export their avocados (Roberts and Orden, 1996) with attractive results. The short shelf life of Mexican avocados is the biggest problem to solve.

In this work, the effort was centered in the elaboration of edible film with ellargic acid at three different concentrations and to evaluate its effect in the physiochemical and microbiological quality of whole avocados.

\section{Materials and methods}

\subsection{Materials}

The wax used in this study was extracted from the plant Euphorbia antysyphilitica, better known by its common name in the Mexican desert region, as candelilla using the commercial process applied by the company CENEMEX ${ }^{\mathrm{TM}}$. Dispersions of ellagic acid (ICN reagents, Monterrey, Nuevo Leon, Mexico) at a concentration of $0.01 \%$ were prepared in a edible film formulated by Saucedo Pompa (2007).

\subsection{Shelf life assays}

"Hass" avocados (Persea americana) were obtained from a local supermarket in Saltillo, México. The fruits were selected taking into account their size maturity, visual absence of microorganisms and damage on the skin. The fruits were later disinfected with a solution of sodium hypochlorite $(0.2 \mathrm{~g} / \mathrm{L})$ for $5 \mathrm{~min}$, and dried at room temperature (Gonzales-Aguilar, Monroy-Garcinia, Goycoolea-Valencia, Diaz-Cinco, \& Ayala-Zavala, 2005).

Edible films were prepared in three formulations named as follows: ECEA, edible coating with ellagic acid; ECC, edible coating without active compound (control film). Negative controls were fruits without edible film (WOC).

Each avocado was immersed for $1 \mathrm{~s}$ into a corresponding formulation (density: $0.86 \mathrm{~g} / \mathrm{mL}$ ). Each fruit was covered with $0.5 \mathrm{~g}$ of edible film. The avocados were weighted before with an analytical balance [Ohaus mode E-02130, Pine Brook, NJ]. Humidity of 45\%. Measurement of the following characteristics was performed during the storage period. They were conserved at $5{ }^{\circ} \mathrm{C}$ by a period of 6 weeks and the physicochemical were evaluated every 8 days.

The lightness of samples was analyzed using the $L$ value in a portable colorimeter (ColorTec-PCM, Clifton, NJ). Changes in their aspect were photographically recorded (with a Hewlett-Packard Photosmart R927 digital camera with a $24 \times$ zoom, Palo Alto, CA). Weight loss was measured with an analytical balance (Ohaus model E-02130). The solid contents were measured with a thermobalance (Ohaus model MB-200). Firmness was measured with a Humboldt universal penetrometer (model H-1200, Chicago, IL). The $\mathrm{pH}$ values were obtained using a $\mathrm{pH}$ meter (Orion model420 , Boston, MA). A slurry was made with a mix of fruit and distillate water $(1: 10 \mathrm{w} / \mathrm{v})$, stirring for $10 \mathrm{~min}$, then an electrode was introduced to measure the $\mathrm{pH}$ value. Water activity $\left(a_{\mathrm{w}}\right)$ was measured with an AquaLab Decagon (series 3, Pullman, WA).

\subsection{Microbiological assays}

All treatments were inoculated with a suspension of $1 \times 10^{7}$ spores of $C$. gloeosporioides. They were conserved at $5{ }^{\circ} \mathrm{C}$ by a period of 6 weeks and were evaluated every 8 days to evaluate the effect of antifungal edible coatings with the addition of antioxidant additives.

The count of UFC was done by the method of counting of fungi and yeasts in food based on the Official Mexican norm NMX-F-255$1978^{8}$, which consists in prepare $100 \mathrm{~mL}$ of a sterile solution of $10 \%$ tartaric acid, which was sterilized in autoclave for $15 \mathrm{~min}$. at $121^{\circ} \mathrm{C}$, cooled at $45-48{ }^{\circ} \mathrm{C}$ and to acidified at $\mathrm{pH} 3.5$. Dilutions of $1: 1000$, of avocado pulp in sterile tartaric acid solution were used. $1 \mathrm{~mL}$ of dilution was added and distributed on petri plates with potato dextrose agar, Two sets of three petri plates for sample were prepared; one set was incubated at $22^{\circ} \mathrm{C}$ for 5 days and another set at $35^{\circ} \mathrm{C}$ for $48 \mathrm{~h}$.

\subsection{Experimental design and data analysis}

Data were analyzed using a complete randomized block design, with three replications. ANOVA and a test of Tukey for means comparison were used to analyze the results.

\section{Results and discussion}

The lightness or $L$ values of the samples were improved by the edible films (Fig. 1). The lightness of WOC samples were sharply damaged $(P<0.05)$ during the period of study; the best results were obtained with ECEA. Ellagic acid antioxidant delays the changes in brightness in greater proportion than fruits WOC, The formulations with the active compound reduce the changes of color by browning, including the control wax (ECC) as compared with samples changes in appearance without wax (WOC). Parameter $L$ related to luminosity is an excellent index for evaluation of color in fruits (Saucedo-Pompa et al., 2007). Maia-Geraldine, FerreiraSoares, Alvarenga-Botrel, and de Almeida-Gonçalves (2008) reported that the implement of edibles films based on agar, chitosan and acetic acid in garlic achieving lower the increase in color, while Tawil Bouchez (2003) reported that the use of a chitosan coating in apples reduced the color change. In another study with tomatoes covered with an edible film, the authors noted that after 22 days of storage, control fruits matured faster than the fruits with deck (Ghaouth, Ponnampalam, Castaigne, \& Arul, 1992).

Ruíz-Cruz (2002) demonstrated the positive effect of adding different antioxidants (independent or mixed) on the inhibition of browning of fresh-cut pineapple. When antioxidants are used in 


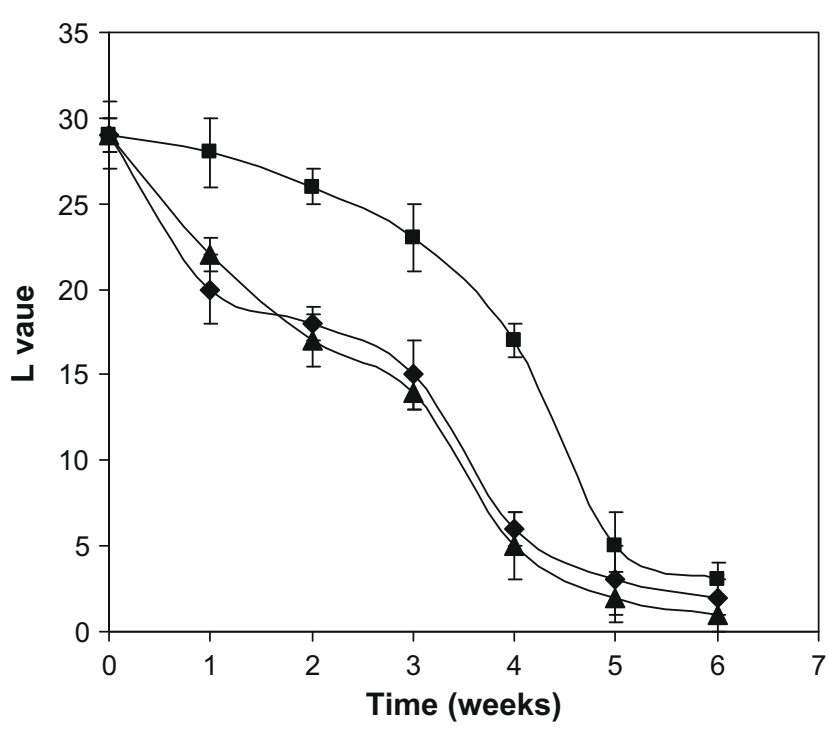

Fig. 1. Effect of edible films on color ( $L$ value) of avocados with ECC ( $)$, ECEA ( and WOC $(\boldsymbol{\Lambda})$.

combination with process technologies such as heat treatments, modified and controlled atmospheres, edible films, gamma radiations and electric pulses, the browning of fruits is inhibited. This study is the first report on the use of a potent nutraceutical agent, ellagic acid as antibrowning additives in fruits, showing excellent results.

All fruits presented changes in their external and internal visual appearances, but the avocados with ECEA suffered a minor change compared with other treatments, especially compared with the WOC avocados (Fig. 2) despite the extreme conditions of contamination. ECC samples suffered a severe damage, but it was lower than that of WOC samples. Polysaccharide films have been used to prevent changes in sliced fruits like lychee, tomatoes, papaya and apples (Buta, Moline, Spaulding, \& Wang, 1999; González-Aguilar et al., 2005). Similar results can be obtained with the new films formulated and applied in this study. And Ghaouth, Arul, and Ponnampalam (1991) reported that the use of edible coatings making slow changes in apple appearance, they argue that it is, due to the modified atmosphere created in the domestic fruit, with high levels of $\mathrm{CO}_{2}$ and low $\mathrm{O}_{2}$ which delayed the maturation processes. The benefits of using ellagic acid with candelilla wax as edible film have been clearly evidenced by Saucedo-Pompa et al. (2007) due they demonstrated that these films improve the color and texture of fruits.

In all samples, the weight loss was increased during the period of study $(P<0.05)$, (Fig. 3$)$. The highest lost of weight was found in WOC samples. The lowest lost of weight was registered in samples with ECEA. The use of ellagic acid as part of edible films diminished the moisture loss in fruits. For fruits, the reduction in weight loss is very important and the use of edible films is an excellent tool to

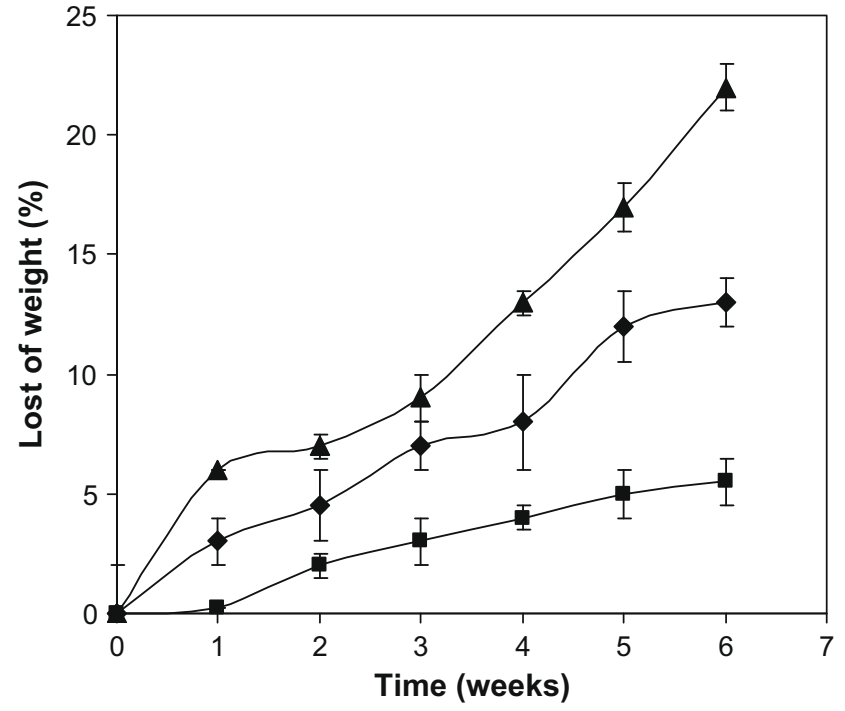

Fig. 3. Effect of edible films on the lost of weight of avocados with ECC ( $\bullet$ ), ECEA (ם) and WOC ( $\mathbf{\Delta})$

control the reduction in weight (González-Aguilar et al., 2005). These results are similar to those found by Kester and Fennema in 1986 who report that the use of lipid-based coating retard moisture loss, just as Assis and Pessoa (2004) reported that these coatings applied to apples reduce the loss of moisture. Guilbert (1988) used casein and carnauba wax in a coating formulation, this edible covers reduce the loss of moisture in papaya, this is due to the barrier that is formed around the fruit, which prevents the loss of water vapor (Ghaouth et al., 1991).

Solids content in avocados with ECEA was higher in comparison with the control treatments. May be, this is related to the accelerated maturation of the control fruits and the corresponding weight loss in the same (Fig. 4) $(P<0.05)$; in this case, volatile and water soluble compounds can be released during the dehydration of control samples. With WOC and ECC treatments, the mass transfer in the surface of fruits is the predominant factor of respiration (Rogers, 1985).

Avocados coated with ECEA $(P<0.05)$, retained the initial firmness values. The firmness of WOC samples was severely affected in comparison with those stored with films containing antioxidants The texture of avocados was improved with the application of edible films similar to the results reported by Ghaouth et al. (1992) for tomatoes.

The $\mathrm{pH}$ values increased during the period of study for all treated samples (Fig. 5). However, this change in pH was significantly low in comparison with WOC samples, while better results were obtained with ECEA $(P<0.05)$.

These results are consistent with those obtained by GonzálezAguilar et al. (2005) they found a decrease in the increase of $\mathrm{pH}$ of papaya treated with covers. On the other hand, Cantwell and

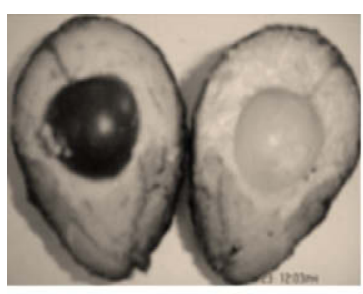

a

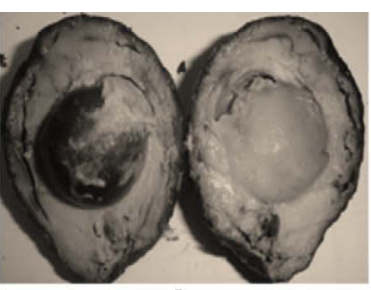

b

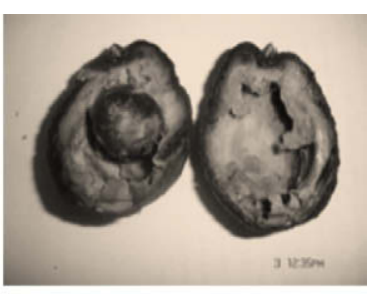

C

Fig. 2. Internal appearance of avocados with ECEA (a), ECC (b) and WOC (c). 


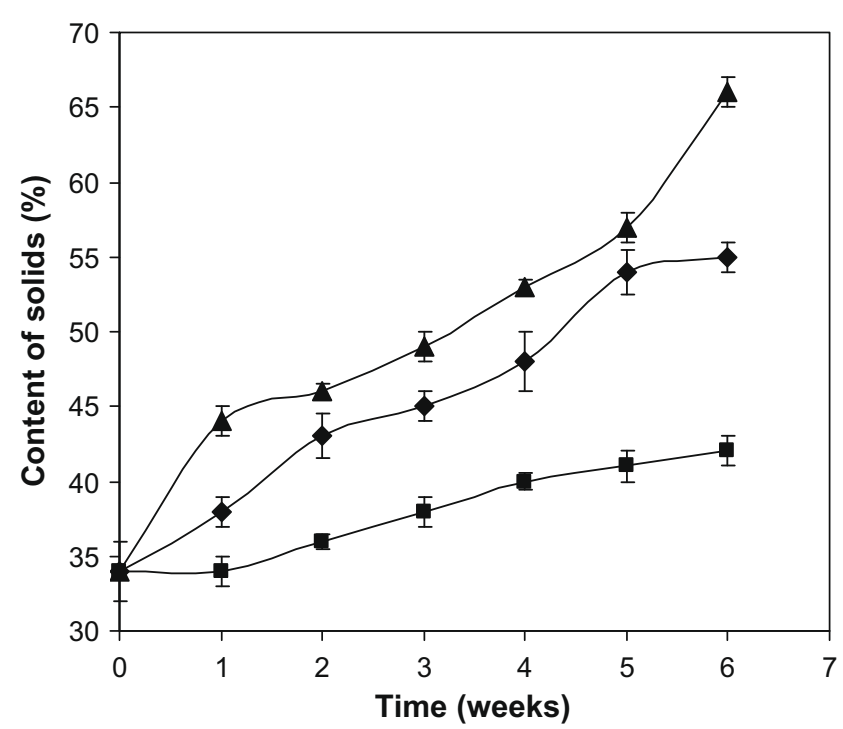

Fig. 4. Content of solids of avocados with ECC ( $\bullet)$, ECEA ( $\mathbf{\square})$ and WOC ( $\mathbf{\Delta})$.

Portela (1997) observed an increase in the $\mathrm{pH}$ of melon stored in an atmosphere of air at $5^{\circ} \mathrm{C}$.

Avocados were significantly benefited with edible films containing ECEA (Fig. 6) $(P<0.05)$. The increment of $a_{\mathrm{w}}$ values in WOC samples because of the accumulation of water was outstanding. The ECC and ECEA samples also showed the positive effect of candelilla wax alone on the $a_{\mathrm{w}}$ values.

The application of the edible films on the external part (cracked) $(P<0.05)$ of the fruit demonstrated to be an effective barrier against the penetration from the fungal contamination to the internal part of the fruit (pulp). ECEA maintains the quality of shelf life what transforms it into the best option of avocados in fresh, all this taking into account the extreme conditions of storage in those that work (Table 1 ). These results are similar to those found by MaiaGeraldine et al. (2008) who reported that the use of agar-based coatings, in garlic delayed $50 \%$ the fungal contamination in this food.

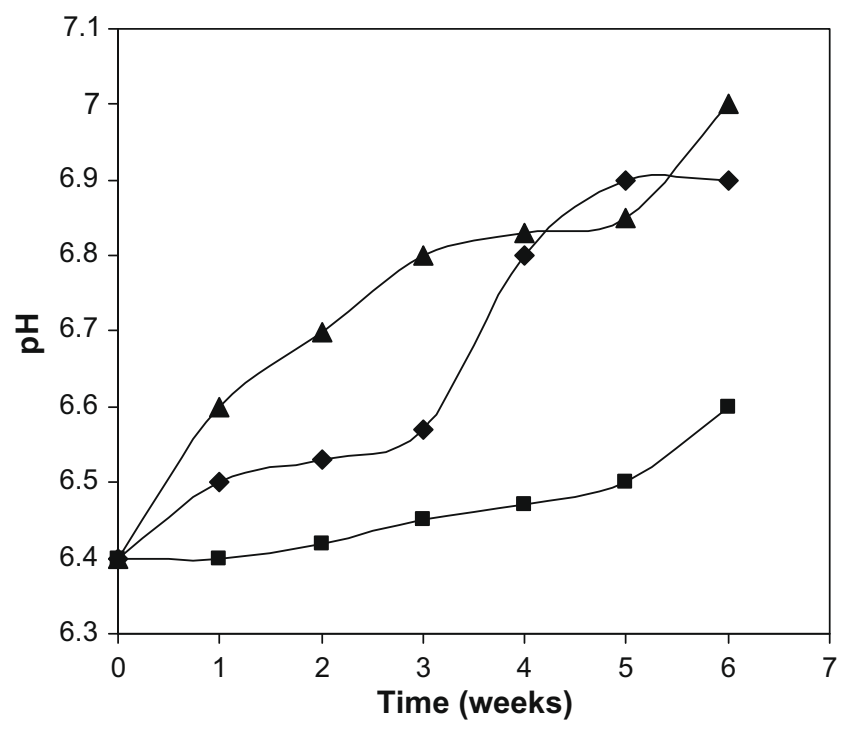

Fig. 5. Effect of application of edible films on the $\mathrm{pH}$ value of avocados with $\mathrm{ECC}(\boldsymbol{\bullet})$, $\operatorname{ECEA}(\boldsymbol{\square})$ and WOC $(\boldsymbol{\Delta})$.

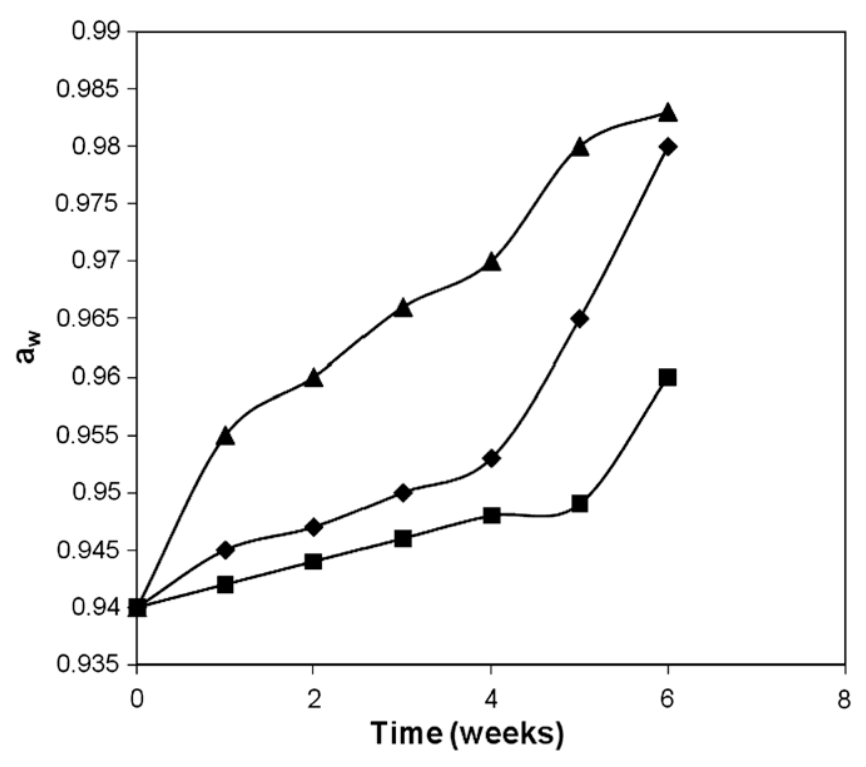

Fig. 6. $a_{\mathrm{w}}$ of avocados with ECC (४), ECEA ( $\left.\mathbf{\square}\right)$ and WOC ( $(\boldsymbol{\Delta})$.

Table 1

Maximal values of the counting of colony forming unit.

\begin{tabular}{lcl}
\hline \multirow{2}{*}{ Treatments } & \multicolumn{2}{c}{ CFU per gram of avocado pulp } \\
\cline { 2 - 3 } & Maximum load & Incubation Time (h) \\
\hline ECEA & 40 & 240 \\
ECC & 67 & 192 \\
WOC & 3373 & 240 \\
\hline
\end{tabular}

\section{Conclusions}

Application of edible films based on candelilla wax and ellagic acid significantly minimized the changes in appearance, solid content, $\mathrm{pH}, a_{\mathrm{w}}$, luminosity and weight loss, maintaining the quality of avocado fruits and prolonging their shelf life compared with other treatments, this without even leaving aside that even the ECC significantly improves the quality of the shelf life of fruits, that because of the atmosphere which creates the application of this EF. These excellent results were obtained considering the extreme conditions of fungal contamination sued in this work. Finally, we conclude that the use of an edible film based on candelilla wax with a potent antioxidant ellagic acid on whole fruits is a good alternative to conserve fresh avocados.

\section{Acknowledgements}

The authors are grateful to the Mexican Program of CONACYTCONAFOR (Project No. 2008-C01) for the financial support of this work. Authors Saul Saucedo-Pompa and Romeo Rojas Molina want to thank to Mexican Council of Science and Technology (CONACYT) by their scholarships received for their postgraduate studies.

\section{References}

Assis, O., \& Pessoa, J. (2004). Scientific note: Preparation of thin films of chitosan for use as edible coatings to inhibit fungal growth on sliced fruits. Brazilian Journal of Food Science, 7, 17-22.

Baldwin, E. A., Medlar-Carriedo, M. O., \& Baker, R. A. (1995). Edible coatings for lightly PRECES fruits and vegetables. Hortscience, 30, 35-37.

Bosquez-Molina, E. (2005). Development of edible coatings made with mesquite gum and candelilla wax for the preservation of fruits. Food Research International, 9, 885-893. 
Buta, G. J., Moline, H. E., Spaulding, D. W., \& Wang, C. Y. (1999). Extending storage life of fresh-cut apples using natural products and their derivates. Journal of Agricultural and Food Chemistry, 47, 1-6.

Cantwell, M., \& Portela, S. (1997). Comparing varieties and storage method. Fresh Cut, 14-18.

Ghaouth, E. L., Arul, J., \& Ponnampalam, R. (1991). Use of chitosan coating to reduce water loss and maintain quality of cucumber and bell pepper fruits. Journal of Food Processing and Preservation, 15, 359-368.

Ghaouth, E. L., Ponnampalam, R., Castaigne, F., \& Arul, J. (1992). Chitosan coating to extend the storage life of tomatoes. Hortscience, 27, 1016-1018.

Gonzales-Aguilar, G. A., Monroy-Garcinia, I. N., Goycoolea-Valencia, F., Diaz-Cinco, M. E., \& Ayala-Zavala, J. F. (2005). Cubiertas comestibles de quitosano. Una alternativa para prevenir el deterioro microbiano y conservar la calidad de papaya fresca cortada. In Proceedings of the Simposium "Nuevas tecnologías de conservación y envasado de frutas y hortalizas Vegetales frescos cortados"(pp. 121133). La Habana, Cuba.

Guilbert, S. (1988). Use of superficial edible layer to protect intermediate moisture foods application to the protect of tropical fruit dehydrated by osmosis. In C. C. Seow (Ed.), Food preservation by moisture control (pp. 119-219). Londres, Reino Unido: Elsevier.

Kester, J. J., \& Fennema, O. (1986). Edible films and coatings: A review. Food Technology, 12, 47-59.

Khanbabaee, K., \& Van Ree, T. (2001). Tannins: Classification and definition. Natural Product Report, 18, 641-649.

Maia-Geraldine, R., Ferreira-Soares, N. F., Alvarenga-Botrel, D., \& de AlmeidaGoncalves, L. (2008). Characterization and effect of edible coatings on minimally processed garlic quality. Carbohydrate Polymers, 72, 403-409.

Mecitoflu-Güçbilmez, Ç., Yemenicioflu, A., \& Arslanoflu, A. (2007). Antimicrobial and antioxidant activity of edible zein films incorporated with lysozyme, albumin proteins and disodium EDTA. Food Research International, 40, 80-91.

Oussalah, M., Caillet, S., Salmieri, S., Saucier, L., \& Lacroix, M. (2004). Antimicrobial and antioxidant effects of milk protein-based film containing essential oils for the preservation of whole beef muscle. Journal of Agricultural and Food Chemistry, 57(18), 5598-5605.

Pranoto, Y., Rakshit, S., \& Salokhe, V. (2005). Enhancing antimicrobial activity of chitosan films by incorporating garlic oil, potassium sorbate and nisin. LWTFood Science and Technology, 38, 859-865.

Roberts, D., \& Orden, D. (1996). Determinants of technical barriers to trade: The case of the US Phytosanitary restrictions on Mexican avocados, 1972-1995. In International agricultural trade research consortium conference on understanding administered trade barriers, Tuscon, Arizona, 14-17 December.
Rogers, C. E. (1985). Polymer permeability. In J. Comyn (Ed.) (pp. 11-73). New York: Elsevier.

Rooney, M. L. (1995). Overview of active food packaging. In M. L. Rooney (Ed.), Active food packaging (pp. 1-37). Glasgow, Ireland: Blackie Academic and Professional.

Ruíz-Cruz, S. (2002). Uso de agentes antioxidantes y envasado en atmósferas modificadas para mantener la calidad de rodajas de piña fresca. MSc Thesis, CIAD, A.C. Hermosillo, Sonora, Mexico.

Saucedo Pompa, S. (2007). Development of edible films from candelilla wax and antioxidants. Thesis, Universidad Autónoma de Coahuila. Saltillo, Coahuila, México.

Saucedo-Pompa, S., Jasso-Cantu, D., Rojas-Molina, R., Sáenz-Galindo, A., \& Aguilar, C. N. (2008). Behavior of a nutraceutical coating made of candelilla wax on the shelf life quality of avocado. In Proceedings of the XXIX national meeting of AMIDIQ (Mexican Academy of Research and Studies of Chemical Engineering) (Vol. 7, pp. 236-244)

Saucedo-Pompa, S., Jasso-Cantu, D., Ventura-Sobrevilla, J., Sáenz-Galindo, A., \& Aguilar, C. N. (2007). Effect of candelilla wax with natural antioxidants on the shelf life quality of cut fresh fruits. Journal of Food Quality, 30, 823-836.

Seydim, A. C., \& Sarikus, G. (2006). Antimicrobial activity of whey protein based edible films incorporated with oregano, rosemary and garlic essential oils. Food Research International, 39, 639-644.

Tawil Bouchez, M. E. (2003). Efecto de cubiertas de quitosano con características hidrofóbicas en la vida de anaquel de zanahorias mínimamente procesadas. Tesis Licenciatura. Ingeniería de Alimentos. Departamento de Ingeniería Química y Alimentos, Escuela de Ingeniería, Universidad de las Américas Puebla, Mexico.

Tharanathan, R. N. (2003a). Biodegradable films and composite coatings: Past, present and future. Trends in Food Science and Technology, 14, 71-78.

Tharanathan, R. N. (2003b). Biodegradable films and composite coatings: Past, present and future. Trends in Food Science Technology, 14, 71-78.

Vasconcellos, J. A. (1994). Functional foods (in spanish). Conceptos y Beneficios Para la Salud. Departamento de Ciencias de Alimentos y Nutrición, Universidad Chapman, Orange, California, USA

Ventura, J., Belmares-Cerda, R., Aguilera-Carbó, A., Contreras-Esquivel, J. C., Rodriguez-Herrera, R., \& Aguilar, C. N. (2008). Fungal biodegradation of tannins from creosote bush (Larrea tridentata Cov.) and tar bush (Fluorecencia cernua) for gallic and ellagic acids production. Food Technology and Biotechnology, 46, 213-217.

Vermeiren, L., Devlieghere, F., van Beest, M., de Kruiif, N., \& Debevere, J. (1999). Developments in the active packing of foods. Trends in Food Science and Technology, 10, 77-86. 